\title{
Selection and use of feeding sites and feeding stations by herbivores: A review
}

\author{
Christine Roguet ${ }^{\mathrm{a} *}$, Bertrand Dumont ${ }^{\mathrm{b}}$, Sophie Prache $^{\mathrm{b}}$ \\ ${ }^{a}$ Station de recherche sur la vache laitière, Inra, Saint-Gilles, 35590 L'Hermitage, France \\ ${ }^{b}$ Laboratoire adaptation des herbivores aux milieux, Inra, Clermont-Ferrand/Theix, \\ 63122 Saint-Genès-Champanelle, France
}

(Received 13 October 1997; accepted 20 May 1998)

\begin{abstract}
A better understanding of the animal $\times$ plant interaction is needed to develop management practices which will maintain a sufficiently rich and abundant vegetation in the pastures. Such practices would permit the animals to meet their nutritional requirements, and to ensure a sufficient production, while contributing to the maintenance of the environment. This review, drawn on a large number of experimental studies, takes stock of the factors influencing the selection and use of feeding sites and stations by herbivores. First, we present the theoretical framework in which the experimental observations are discussed. The general context of optimal foraging theory (OFT) and its predictions are described. Its 'applicability', usefulness and validity to study the foraging behaviour of herbivores are then discussed. Second, we analyse how forage (quantity and quality, plant species, distribution), environment (topography, distance to water, predator risk) and some animal factors (cognitive abilities, social organisation) affect the choice and use of feeding sites and stations. In spite of some problems of definitions ('patch', 'prey' for an herbivore?) and of the herbivores' specific characteristics, the OFT has been successfully used to explain the foraging behaviour of herbivores. However, animals' choices are rarely as absolute as predicted. Under natural conditions, animals not only respond to food resource, but are also constrained by some non-alimentary environmental factors and by the limits of their cognitive abilities (memory, discrimination). Other complementary approaches, such as 'hedonism' and 'nutritional wisdom', can partly influence animals' choices and are also briefly discussed. (C) Elsevier/Inra)
\end{abstract}

grazing / herbivores / diet selection / optimal foraging theory / feeding site / feeding station

Résumé - Sélection et utilisation des sites et stations alimentaires par les herbivores : Une revue. À terme, mieux comprendre la relation animal - végétation est nécessaire pour développer des systèmes de gestion qui favorisent le maintien par le pâturage d'une ressource suffisamment riche et abondante. Dans ces conditions, l'animal peut couvrir ses besoins nutritionnels et assurer une productivité suffisante, tout en participant à l'entretien du milieu. Cette revue fait le point, à partir d'un grand nombre de travaux expérimentaux, sur les facteurs qui influencent la sélection et l'utilisation

* Correspondence and reprints

Tel.: (33) 02992850 86; fax: (33) 02992851 01; e-mail: roguet@st-gilles.rennes.inra.fr 
des sites et stations alimentaires par les herbivores. La première partie est consacrée au cadre théorique dans lequel sont discutées les observations expérimentales. Le contexte général de la théorie de l'alimentation optimale (TAO), et ses prédictions, sont décrits. L' « applicabilité », l'utilité et la validité des modèles d'optimisation dans l'étude du comportement alimentaire des herbivores sont tout particulièrement considérées. Ensuite, est étudiée l'influence des différents facteurs, trophiques (quantité et qualité des ressources fourragères, distribution des espèces végétales), environnementaux (topographie, distance aux points d'eau, présence d'abris et risques de prédation) et animaux (capacités cognitives et organisation sociale) sur la sélection et l'utilisation des sites et des stations alimentaires par les herbivores. En dépit de quelques problèmes de définitions (patch, proie pour un herbivore ?) et des caractéristiques spécifiques des espèces animales étudiées, la TAO a pu être appliquée, avec succès, à l'étude des stratégies alimentaires des herbivores. Cependant, les choix ne sont en général pas aussi absolus que ceux prédits par la théorie, En conditions naturelles, les animaux répondent non seulement à la ressource alimentaire, mais aussi à différentes contraintes externes (environnement non alimentaire) et internes (mémoire, discrimination, etc.). D'autres approches complémentaires, telles l'« hédonisme» et la « sagesse nutritionnelle », susceptibles d'influencer les choix des animaux, sont aussi brièvement analysées. ( Elsevier / Inra)

pâturage / herbivores / sélection / station alimentaire / site alimentaire / alimentation optimale

\section{INTRODUCTION}

When grazing, an animal has both to search for and harvest its food. Its foraging behaviour is affected by climatic, topographic and predatory constraints. Forage characteristics of habitats also influence the spatial distribution of herbivores, their diet (intake, choice) and their impact on the environment. A better understanding of the animal $\times$ vegetation interaction is needed to develop management practices which will maintain a sufficiently rich and abundant vegetation in pastures. Such practices would permit the animals to meet their nutritional requirements and to ensure a sufficient production, while contributing to the maintenance of the environment.

The grazing process can be seen as the result of a series of decisions taken by the animal at different spatio-temporal levels [122]. In the long term, animals choose their habitat and the time they allocate to foraging. Within their habitat, they select 'feeding sites' on which they choose and graze 'feeding stations', i.e., the sward surface accessible to an animal without moving its forefeet [43]. Finally, they select bites within a feeding station at the 'tussock' level.
Under harsh pasture conditions, intake and time per bite are the factors limiting the daily intake of nutrients [53]. Through feeding site selection, herbivores can increase their intake rate [21, 68]. However, when resources are very scattered or heterogeneous, prehension biting rate and intake rate can be limited by the time to move between sites [127, 131].

More simply, grazing can be considered as the alternation of 'step-sets/moving time' between feeding stations and of 'bitesets/grazing time' within feeding stations $[52,76,134]$. This breakdown makes it possible to determine for each diet the relative contribution of feeding station selection in the paddock and of bite choice on the feeding station. In addition, some authors [ 10 , $63,93,125,138]$ used this breakdown to define the idea of a 'feeding site' for continuous resource situations. A 'feeding site' is defined as 'a group of feeding locations located a short distance apart'. The distance between feeding sites is then much longer.

In this review, we analyse how trophic (forage quantity and quality, plant species, distribution), environmental (topography, distance to water, shelter, predator risk), and 
some animal (cognitive abilities, social organisation) factors influence the choice and use of feeding sites and stations. Experimental observations are discussed, particularly in relation to optimal foraging theory models.

\section{THEORETICAL FRAMEWORK: OPTIMAL FORAGING THEORY}

\subsection{General context}

In the long term, a behaviour is said to be 'optimal' when it enables the animal to maximise its contribution to the subsequent generation ('fitness'). This involves the maximisation of survival and reproduction probabilities. The optimal foraging theory (OFT; $[35,75,102,107])$ predicts the behaviour of animals when foraging. Conventional models maximise the net rate of energy gain. This currency, chosen a priori largely on the basis of intuition, takes into account two major elements of the foraging activity: the energy in terms of benefit and cost and the time [130]. Laca and Demment [70] considered this currency had the major limit that: "it only took into account the nutritional and energetic consequences of feeding'. However, it seems very difficult to construct a global optimisation model, which would take into account all the compromises an animal has to make between its different demands, while remaining functional [88]. Mangel and Clark [79] developed a class of unified behavioural models, which included finding food, avoiding predators and reproducing. They called it 'unified foraging theory' because foraging is a key behaviour for an animal, except during hibernation and rut. But, the degree of realism of their theory is severely constrained by its large computational demands [70]. Moreover, the aim of a model is not to perfectly imitate reality with thoroughly detailed outputs, but to give general rules that improve our understanding of behaviours.

\subsection{Application to herbivores}

OFT models were first developed on insects [14, 16, 51, 104], birds [15, 72, 74, $105,126]$ and rodents [73]. These animals forage on 'preys' of a high and relatively uniform nutritional value, concentrated in discrete 'patches'. The transfer of this theory to herbivore foraging behaviour raises problems of definitions (what is a 'patch' or a 'prey' for a herbivore?) and others related to the specific characteristics of herbivores (digestion, cognitive abilities, social structure).

The food resource herbivores exploit is generally continuous, making the definition of a 'patch' difficult. This is often considered to be the major difficulty for testing optimal foraging predictions. A broad definition of 'a patch' is 'a surface which differs from its surrounding with respect to its nature and its appearance' [145]. According to Pickett and White [95]: "patch implies a relative discrete spatial pattern, but does not establish any constraint on patch size, internal homogeneity or discreteness'. In addition, Forman and Godron [38] noted that: 'patches vary widely in size, shape, type, heterogeneity and boundary characteristics'. Hence, patches have to be defined in relation to the animals and questions under study. Sih [124] defined 'patches' as: "entities which require search or pursuit time between periods of energy intake". For herbivores, this definition corresponds to food resources that are reasonably long distances apart, i.e., to feeding sites or larger units of selection. A feeding site can be small (a single feeding station) or very broad (many stations). On continuous vegetation, and especially on homogeneous ground covers, feeding sites are generally rare and large. The animal grazes many feeding stations that are only short distances apart before it starts (less frequently) a long walk towards a new feeding site. Conversely, the resources can be distributed as very scattered individual feeding stations, either naturally (desert vegetation; [142] or artificially (mown or 
hand-constructed sward plates, trees in a cut paddock; [5, 10, 24, 68]. In this latter case, feeding site identification is easier.

The nutritional value of herbivore food resources is usually low and variable in time and space. Therefore, the time to harvest the nutrients that will make them meet their requirements can be a major constraint. This time is limited by the time allocated to other activities, such as rumination, resting, social interactions, predator scanning, search for sexual partners, etc. In a changing environment, the animal also has to sample its resources to check their value and discover new foods. As herbivores eat long meals during which they ingest numerous plant species, it is difficult for them to sort out the individual effects of each choice [26]. They express preferences between resources (plant species, plant parts with different fibre contents), and make trade-offs between the quantity and quality of the food they ingest, both at the site and station levels (tall and mature sward vs. short and vegetative sward; [29]), and at the tussock level (stems vs. leaves; [96]).

\subsection{Predictions}

Pyke et al. [102] classified optimisation models into four groups, depending on whether they predict, for an individual, (1) diet choice, (2) patch choice, (3) patch use, or (4) movement. In this paper, we are interested in the last three points. Other models such as the ideal free distribution (IFD; [39]) do not predict the distribution of the foraging activity of an individual between the available resources, but how individuals in a population distribute themselves in the habitat.

\subsubsection{Optimal patch choice}

Initial optimal patch choice models involve the following assumptions [107]: a) animal has complete knowledge of the location and value of each patch; b) patch location and value remain constant over time; c) patch resource availability does not decrease during the time the animal spends in the patch; and d) 'fitness' increases linearly with intake rate.

From these assumptions, the OFT predicts that an animal will spend all its time in the patch with the highest intake rate $[73,92]$.

However, a) is partly disproved by the limits in the discrimination capacities and memory of herbivores. b) and c) seldom hold true in natural situations where vegetation changes with time and animal consumption on the patch progressively depletes it. At last, d) has never been confirmed for herbivores. If fitness is a non-linear function of intake rate, or if it also depends on a specific nutrient, the optimal choice would be not to allocate all the time to a single patch, but rather to distribute it between different sites and to allow time to sample the different alternatives [107].

\subsubsection{Optimal patch use}

The classical model of optimal use of patchily distributed resources is the marginal value theorem (MVT; [17]). An animal that seeks to maximise its intake rate will leave a patch when its marginal (i.e., instantaneous) intake rate in that patch falls below the average intake rate in the habitat. The animal is assumed to have complete knowledge of its environment and the predatory risk is assumed to be null. In addition, resource depletion due to animal foraging decreases intake rate, and moving to a new site is time and energy consuming.

The MVT predicts: 1) in an homogeneous environment (a single patch type): i) the optimal grazing time per patch, from the intake curve on the patch and the moving time between patches. Patch grazing time increases with patch value (figure la); ii) the relationship between optimal grazing time per patch and moving time between patches. Grazing time per patch increases with moving time between patches (figure $(b)$; 2) in an heterogeneous environment: patches are gra- 

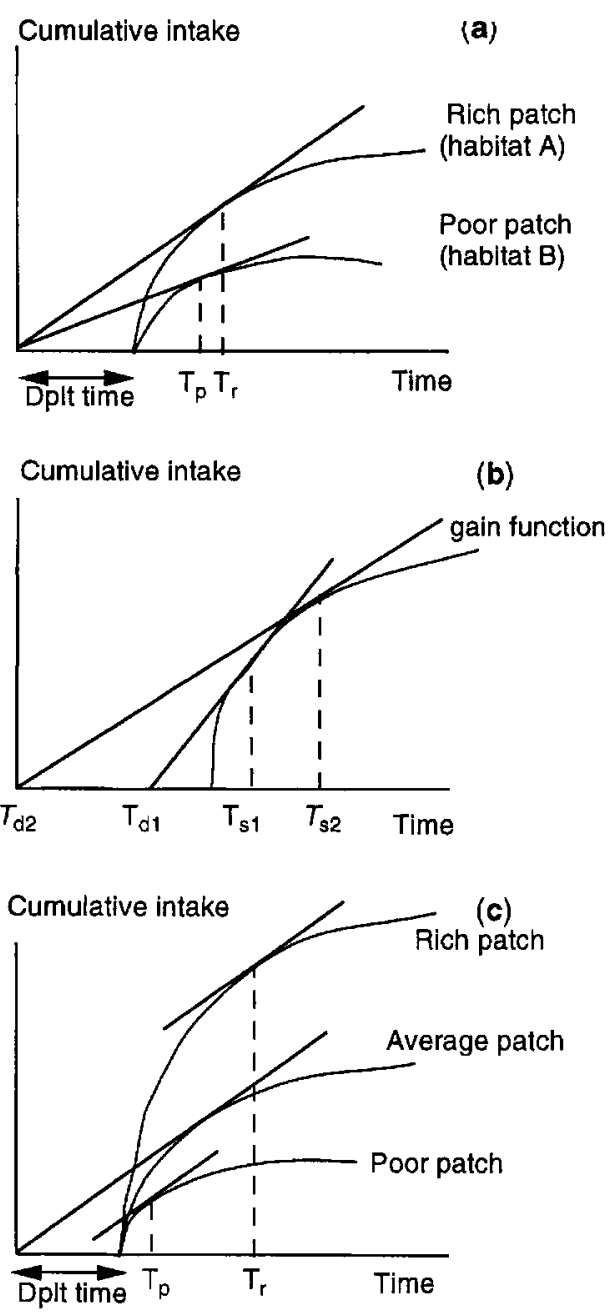

Figure 1. Prediction of the optimal grazing time per patch using the marginal value theorem [17]. a. Relationship between the grazing time per patch and the value of the patch (Tp, time in the poor patch; $\mathrm{Tr}$, time in the rich patch). b. Relationship between the grazing time per patch and the moving time between patches (Tsi, patch grazing time for a moving time Tdi). c. Grazing time per patch in a heterogeneous environment with feeding sites of different values.

zed up to the same marginal value of intake rate (average intake rate of the habitat). Animals will graze a rich patch longer than a poor one (figure $1 c$ ).

\subsubsection{Optimal movement}

Optimising movement implies walking a minimal distance between the selected patches. This problem ('travelling salesman problem'; [1]) is so difficult to solve $((n-1)$ ! alternatives for $n$ patches) that an animal is unlikely to find the optimal solution. The most efficient suboptimal solution consists of walking to the nearest preferred patch ('nearest neighbour rule'; [104, 133]). Between patches, an animal walks in a straight line to avoid repeated use of the same patches ('directionality'; [103, 106]). Within the patch, it increases its travel sinuosity (i.e., shows klinokinesis) and reduces its walking speed (i.e., shows orthokinesis) when a 'prey' (rewarding feeding station) has been found in the hope that some others may be close by ('area-restricted searching'; [103]).

\subsubsection{Animals' optimal distribution in the habitat: 'habitat matching'}

Ideal free distribution (IFD; [39]) predicts the optimal distribution of individuals among the different patches of their habitat. The different hypotheses are as follows: a) individuals seek to maximise their feeding efficiency (energy gain/cost); b) they have complete knowledge of their environment ('Ideal'); c) they undergo no constraint to choose their sites ('Free'); d) they have equal competitive abilities; e) intake per animal decreases when the number of animals in the patch increases; and f) distance between patches does not significantly affect animal distribution.

In this case, the IFD predicts that the proportion of animals in a patch will be equal to the proportion of resources in this patch. This relationship is also called 'habitat matching'.

Once again, assumption (b) comes up against the limits of animals' spatial memory. Group living is contrary to (c). Moreover, contrary to (d), animals do compete with each other and they do not have 
equal competitive abilities [56]. Finally, movement between patches (f) generally cannot be considered as insignificant. Moving costs and gregariousness may induce 'overmatching' (overexploitation of the rich patches), whereas difficulties in discriminating patch value and limits in spatial memory may lead to 'undermatching' (overexploitation of the poor patches) [64].

\section{INFLUENCE OF FOOD RESOURCES}

Currently, the expression 'selection of site $S$ ' is often used to indicate the result of two distinct phenomena: 1) the animal prefers to visit the site $\mathrm{S}$ (number of visits); and/or 2) at each visit, it exploits the site more intensely (grazing time, bite number, intake). For example, selection of tall sward patches by ewes (between two possibilities: 12 vs. $7 \mathrm{~cm}$ ) did not result from a higher number of visits as the animals visited both plates in turn (after they had first grazed the taller in $68 \%$ of the tests). However, they grazed the taller patch more intensely [59]. Similarly, Vivas and Saether [137] (moose), and Distel et al. [24] (cattle) showed that these animals did not visit the rich patches in the habitat more frequently, but that the grazing intensity on each patch (grazing time, intake) was positively related to the patch richness (figure 2). In these cases, use of the expression 'selective use' rather than 'selection', would be more appropriate.

Herbivores choose and use their feeding sites according to their nutritional value and their distribution in the habitat (distance, aggregation; figure 3). Patch nutritional value depends on its resource quantity (biomass), structure (height, density), quality (digestibility, nitrogen and secondary compound content) and nature (plant species). The amount of contrast between different patches defines their relative interest. Aggregation level modifies moving constraints and influences the relative use of the different patches. At the feeding station level, factors affecting grazing decisions seem to

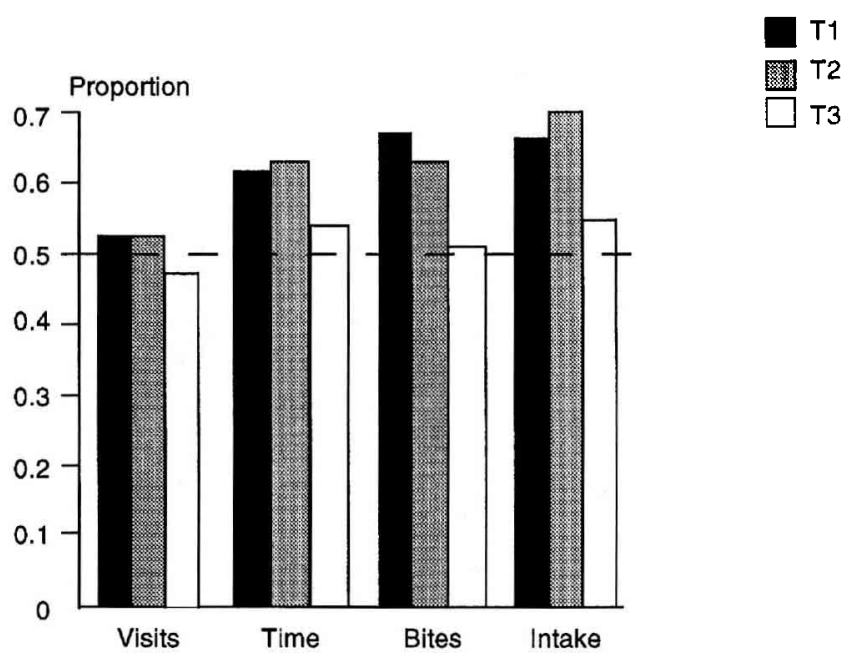

Figure 2. Distribution of the number of visits, the grazing time, the bite number and the intake between two patch types. The control patch type, present in all the three treatments, has a sward height of $7.5 \mathrm{~cm}$ and a density d. For T1, the alternative patch had a sward height of $12 \mathrm{~cm}$ and a density d. For $\mathrm{T} 2$, it had a sward height of $7.5 \mathrm{~cm}$ and a density d/2, and for $\mathrm{T} 3 \mathrm{a}$ sward height of $12 \mathrm{~cm}$ and a density $\mathrm{d} / 2$. Each experimental plot was a $10 \times 10 \mathrm{~m}^{2}$ paddock consisting of a square arrangement of 16 patches of $0.6 \times 0.6 \mathrm{~m}^{2}$ in four columns and four rows separated by $1.5-\mathrm{m}$ wide alleys [24]. 
be less clear. We will discuss the reasons for this, and present some hypotheses and conclusions.

\subsection{Influence of patch nutritional value}

\subsubsection{Herbivores choose sites with the highest intake rate}

In agreement with OFT predictions, animals generally select feeding sites that permit them to have the highest intake rate. When offered two plates with structurally different swards (height and density), sheep usually prefer the sward they can eat faster $[13,59]$. Intake rate depends on patch resource availability, but also on ease of prehension. For herbivores, ease of prehension may be related to sward structure (density, height) and fibre characteristics (resistance to shearing; $[57,97])$.

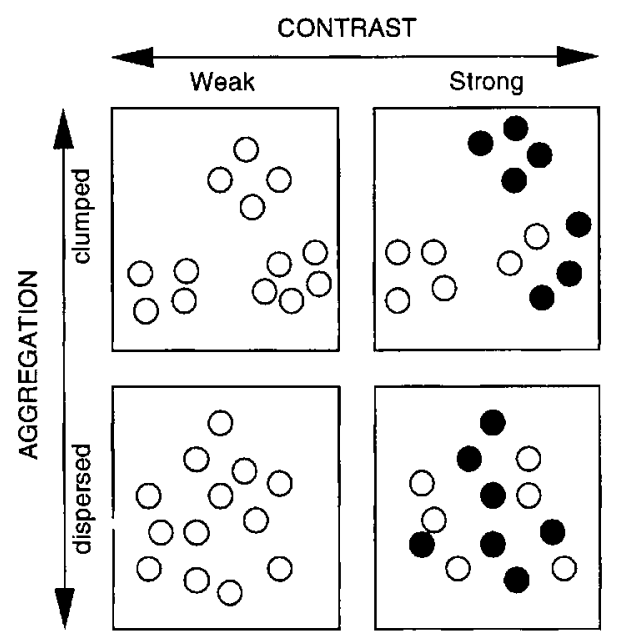

Figure 3. Diagram showing the contrast and aggregation levels between sites [150]. When contrast is weak (null, only one patch type), the study focuses on patch use in relation to patch's absolute value and distance between patches when aggregation level varies. When contrast between patches increases, selection and use of patches vary with their relative value.
Herbivores do not seem to be able to estimate intake rate a priori. To select their feeding sites, they rely on intake rate cues such as sward height $[21,59,68]$ and to a lesser extent density, a factor that is more difficult to estimate visually [10]. Illius et al. [59] observed that intake rate differences between two sward plates explained only $18 \%$ of the intake distribution variance, whereas differences in sward height and clover content explained $60 \%$. Brightness also indicates nitrogen rich patches [10]. Finally, herbivores use information gained when grazing sites to reinforce the exploitation of the more profitable sites [24, 59].

Dietary preferences also influence patch choice and partly explain diet selection. However, these may be subordinate to the instantaneous intake rate maximisation process: goats offered a choice between five sward species (in pairs on plates at the same sward height) selected a diet which tended to maximise their instantaneous intake rate rather than expressing a preference for some of the plant species [60]. Similarly, under natural grazing situations, cattle, horses, and deer, all selected a diet that mainly included plant species with the highest organic matter intake rate (cattle $58 \%$, horses $52 \%$, deer $72 \%$ ) [136]. The remaining proportion seemed to indicate that $\mathrm{OM}$ intake rate maximisation was not the only rule involved.

In general, the quality of food resources varies inversely with the quantity. For example, a mature sward is tall but of low nutritional value, whereas a vegetative sward is short but of high nutritional value. Hence herbivores have to make a compromise between intake rate over the short term and food processing rate over the longer term [86, 139, 147, 148]. Wilmshurst et al. [148] offered wapitis regrowths of $2,4,6,8$ and 10 weeks that each covered $20 \%$ of a paddock area. Wapitis preferentially used $(30 \%$ of grazing time) the patches with medium biomass and quality (4-week regrowth) rather than the 2-week patches (better quality but low availability; $2 \%$ of grazing time) or the 
6,8 and 10 -week patches (higher availability but lower quality; 26\%, 24\%, and $18 \%$ of grazing time). Wallis de Vries and Daleboudt [139] observed that cattle selected mature feeding sites only when the exclusive use of short vegetative patches did not allow them to fulfil their daily requirements in a restricted time. Similarly, sheep and cattle progressively switched to less preferred food resources (reproductive sward strip at pasture or bad hay indoors) when their preferred forage (vegetative sward strip at pasture or good hay indoors) became less accessible $[28,29]$.

Selection of the most profitable patches is even more apparent when there is a high degree of contrast between patches [139]. For example, when foraging on 16 patches (sward plates) presented in line every $1.2 \mathrm{~m}$, with a mean sward height of $10 \mathrm{~cm}$, cattle only chose the tallest ones when height difference was large, 15 vs. $5 \mathrm{~cm}$ (figure 4). Conversely, they partly switched to the less profitable patches when contrast was reduced $(12.5$ vs. $7.5 \mathrm{~cm})$ thereby decreasing selection profit [68], while increasing discrimination difficulty [139].

\subsubsection{Herbivores express matching patterns in their choices}

Herbivores' choices are indeed generally not as absolute as predicted by the OFT. Herbivores often match the time they spend in an area with the resources found there. An animal can graze the different alternatives in proportion to their relative value ('strict matching'). It can also overexploit the rich patches ('overmatching') or, on the contrary, underexploit them ("undermatching') [71, 122]. Predictive equations of population distribution in the habitat can be adapted to predict the distribution of an individual's foraging behaviour between its food resources (table I).

Behaviours related to 'matching' have been frequently observed in various herbivore species: moose [92, 137], wapiti [71, 148], sheep [59, 60] and cattle [24]. In general, these behaviours are explained by the need for a regular sampling to update the values of the different patches in a complex and changing environment, i.e., an adaptation over the middle rather than the short term [126], or more simply as an imprecise discrimination of patch value $[60,147,148]$.

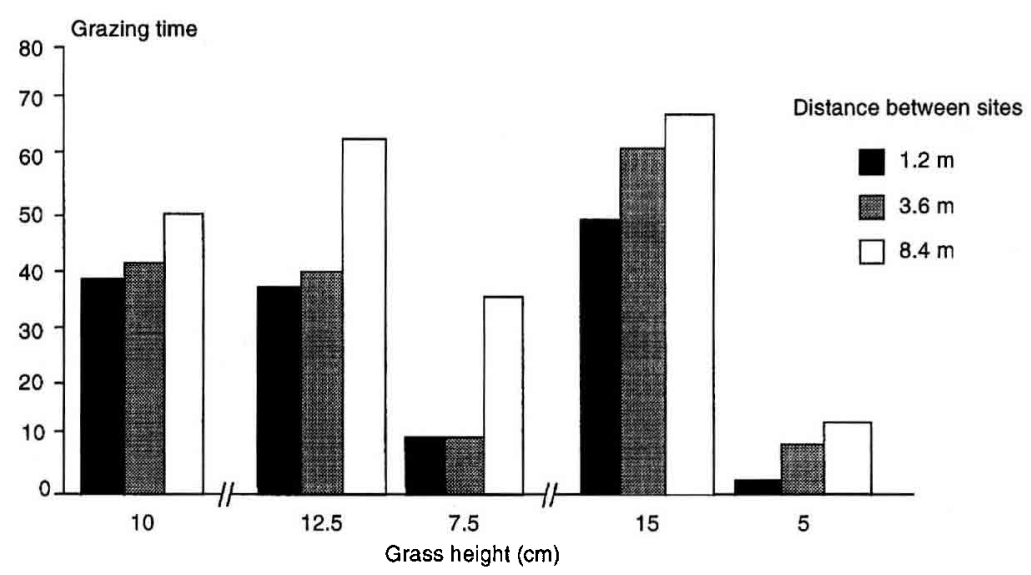

Figure 4. Patch grazing time of cattle as a function of the distance between patches and patch heights. Steers grazed on nine 'environments' formed by combinations of three distances between patches (1.2, 3.6 , and $8.4 \mathrm{~m}$ ) and three sward heights (all sites at $10 \mathrm{~cm}, 8$ sites at 12.5 and 8 at $7.5 \mathrm{~cm}, 8$ sites at

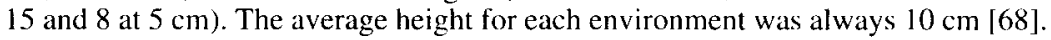


Matching was also related to the 'recognition time' necessary for the animal to assess a patch value when entering it [107]. Furthermore, it could simply result from the decrease in the value of the high quality patches when exploited that leads animals to switch progressively to initially less profitable ones [50]. Finally, when the high quality patches are scatterly distributed, animals can take advantage of poor quality patches while walking to a richer patch.

\subsection{Effect of the spatial distribution of the feeding sites in the habitat}

\subsubsection{Movement constraints}

In order to maximise its intake rate, a herbivore has to make a trade-off between 'to stay in a patch whose food availability is decreasing' and 'to move to a richer patch', i.e., between intake rate depression due to food depletion on the patch, and intake rate reduction due to moving time [69].

When the moving time between sites increases, this compromise results in a more intense site exploitation $[10,21,68,114$, 123] (see figure 4), as predicted by intake rate maximisation models [17]. The grazing times observed (To, s) by Laca et al. [68] were close to the quantitative prediction (Tp, s) of the MVT, in particular for long grazing times $(\mathrm{To}=7.7( \pm 3.61)+0.9( \pm 0.09)$ $\mathrm{Tp}, \mathrm{r}^{2}=0.89$ ). The compensation for the increased distance between patches by an increase in intake per patch may be more than complete [21]. In practice, for the same biomass per hectare, a heterogeneous food distribution seems to be more profitable in terms of intake per selective animal than a more homogeneous distribution.

On continuous preferred vegetation, rules of movement are of little importance as the encounter rate with the food resource is not a limiting factor [127, 142]. When these resources are abundant, high intake rates allow animals to allocate more time to search for preferred feeding sites. Animals can also masticate large bites while walking long distances. Nevertheless, animals tend to limit the distances travelled. When foraging on hand-constructed patches of alfalfa plants set in a very short pasture, bighorn sheep typically moved from one plant to the nearest one ( $75 \%$ of the moves), or to one of the three nearest ( $90 \%$ of the moves; [48]). The 'nearest neighbour rule' seems to apply when the animal can see the available patches and when they are of equal value.

Table I. Optimal distribution of the feeding activity of an individual among the different patches of its habitat (adapted from [64]).

Optimal distribution of the feeding activity of an individual among the food resources of its habitat is given by the relationship:

$$
\mathrm{N}_{1} / \mathrm{N}_{2}=\mathrm{R}_{1} / \mathrm{R}_{2}
$$

with $\mathrm{Ni}$ representing the number of bites, or the grazing time, or the amount ingested and $\mathrm{Ri}$ the intake rate on site $\mathrm{i}$

More precisely, 'matching' laws can be described by

$$
\mathrm{N}_{1} / \mathrm{N}_{2}=\text { b. }\left(\mathrm{R}_{1} / \mathrm{R}_{2}\right)^{\mathrm{a}}
$$

where $\mathrm{a}$ is an estimate of the sensitivity to the reinforcement. $\mathrm{a}=1$ corresponds to 'strict matching', $\mathrm{a}<1$ to 'undermatching' and $\mathrm{a}>1$ to 'overmatching'.

$b$ is an estimate of bias which corresponds to any preference for one site over another not accounted for by the reinforcement ratio. It covers the potential influence of factors such as predator risk, topography, water location, etc. 
When sites are more distant, some models assume that the animal uses its memory to move directly to the preferred patches [133]. The animal may also choose to move at random until it encounters an interesting site [113].

In heterogeneous pastures, patch choice can considerably increase distance travelled [131]. Animals usually compensate for moving time constraint by walking faster $[3,30,94,112,123,127]$. They can also partly switch to less preferred patches [28, 42]. For example, ewes increased the time spent eating a poor quality hay available ad libitum when the distance to walk for a good hay offered in limited quantities increased [30]. In fact, preference for a good hay was the same when $2 \mathrm{Qg}$ of good hay rewarded a $46 \mathrm{~m}$ walk as when $\mathrm{Q} g$ of good hay rewarded a $23 \mathrm{~m}$ walk. The decision to move was not related to the absolute value of a patch but rather to its procurement cost, i.e., the ratio of reward to distance. When modelling the foraging behaviour of moose, Roese et al. [113] successfully used a similar movement rule: animals assessed the profitability of each tree based on edible biomass and distance to the plant.

\subsubsection{Effect of site distribution type (random, uniform, aggregated)}

Clarke et al. [18] studied how sheep and deer used a preferred Agrostis/fescue sward distributed either as 1 large, 4 medium or 12 small sites within a moorland pasture. For each distribution, the sward represented $20 \%$ of pasture area. Sward distribution did not affect the choice of deer but influenced that of sheep. The more the grass was dispersed, the more the ewes grazed the heather: 9,25 and $43 \%$ of foraging time for the 1,4 and 12 grass-site treatments. This switch to heather was attributed to an increase in border zone. Sheep also encountered more frequently heather when moving between grass patches. Due to the faster resource depletion of the small compared to the large grass sites, these moves were more frequent in the 12-site treatment. Strong patch aggregation in the habitat and the subsequent overgrazing of these aggregated resources has a double disadvantage: 1) for the animal a strong reduction in the availability of its preferred species; and 2) for the plant a difficulty to survive when heavily grazed [31].

\subsection{Feeding station choice and use within feeding sites}

Factors affecting foraging decisions and assessment of costs and benefits are likely to apply at every level, from habitat to bite selection [67]. However, the finer the scale, the smaller the associated costs and benefits, and the harder they probably are to assess by the animal. Indeed, 'there is evidence from operant conditioning experiment that the marginal value of many behaviour declines with increasing rate of behaviour' [129]. Within a patch, the benefit of selecting a given feeding station, which would necessitate to gain sufficient information, is relatively small in comparison with a more random search [140], particularly as the short travels between stations make it possible to quickly correct a selection 'error'. The high number of stations within a site, their small size, the small differences in their resources imply that the animal would have to make a considerable effort to discriminate their relative profits. Furthermore, it is impossible for him to remember the precise location of so many alternatives in the habitat.

Arditi and Dacorogna [2, 3], and later Focardi et al. [36] proposed the existence of a critical biomass (threshold) per station; that could be used to distinguish selected from refused stations. An animal foraging on a continuous food resource would graze a station along its foraging path if the biomass available at this point is above this threshold, and would go on walking if it is below. The acceptance threshold would be influenced by recent experience (encounter 
with a high/low quality station raises/lowers this threshold), and by the satiation level of the animal [122].

The use of intake rate in the decision to abandon a feeding station [17] is made difficult by two cumulative phenomena: 1) as the distances between stations are often very short, the residual effect of the grazing rate at the previous station may affect the intake rate estimation at the subsequent station; and 2) this residual effect is even stronger when the feeding station residence time and intake during a visit are small, and may prevent the animal from experiencing an intake rate depression [59]. Senft et al. [122] suggested that, within a site, diet selection was an 'instantaneous maximisation' process that would dictate sequential acceptance of the more palatable food items encountered at each station, probably until palatability dropped below a certain level. The animal would stop grazing on a station when most of the green forage had been fully consumed [131]. It would be interesting to determine if the feeding station departure 'rule' is an absolute threshold (residual biomass or sward height) or a relative one, i.e., an almost constant proportion of available biomass [65, 137], sward height or green leaf mass. Whatever the rules used by an animal, the thresholds are reached later on rich stations than on poor stations: hence grazing time per station (and intake) increases with resource availability in the feeding station $[34,89$, $111,112,115,118,123]$.

Jiang and Hudson [63] showed that neither a given bite number, nor a given grazing time, nor the prehension biting rate decrease (below the mean value for the season) were used as feeding station departure rules by wapiti. The unique indication was the neck angle, almost constant when the animal left a station, which for the authors suggested the important role played by biokinetic factors in this decision. Intake rate was not tested as option in their study.

\subsection{Conclusion}

Most studies show that herbivores' responses to the dietary constraints of their environment are in agreement with the qualitative predictions of intake rate maximisation models. For instance, grazing time per site increases with site value and/or distance between sites. However, animals' choices are rarely as absolute as predicted by OFT models. In general, animals express partial preferences.

Quantitatively, most of the few experiments $[5,10,15,24,110]$ showed large differences between observations and OFT predictions. Three reasons are usually proposed:

1) The precise determination of the patch and station values in terms of intake rate and of the gain curves is particularly difficult even under controlled conditions [60]. But, the shape of these gain curves has a very strong effect on the optimal grazing time [5, 24].

2) The OFT is based on strong assumptions that are not realistic for herbivores (e.g., a complete knowledge of the environment). Moreover, the time scale on which this theory applies has yet to be defined. Wallis de Vries and Daleboudt [139] suggested that herbivores maximised energy intake not on an instantaneous scale but rather on a daily basis. It may, therefore, be impossible to validate optimisation model predictions using short duration tests. However, the longer the time scale, the more difficult to predict the quantity and quality of resources. Hence, it is also unlikely that decisions about patch choice are taken on a scale longer than a few days [141].

3) Animal decisions about patch choice and use are not only influenced by food factors, but also by their non-alimentary environment and their own characteristics. This is what we will discuss in the next sections.

The usefulness of the OFT is yet not discredited for the study of herbivore foraging behaviour [59, 70, 136, 147]. Rather its predictions should be considered as references 
against which to compare the behaviour of animals in various situations. Differences between the observed and predicted values will generate new assumptions which can then be integrated into the models and, by 'iteration', improve our understanding of foraging rules [93].

\section{INFLUENCE OF THE NON- ALIMENTARY ENVIRONMENT}

Patch value is related to forage quantity and quality, i.e., the 'site forage value', but also to abiotic factors such as predator risks, distance to water, shelter, micro-climate and topography that determine the "perceived (global) site value' [8].

Predator risks limit intake rate maximisation via: 1) a time/energy cost of vigilance, which can be important: 2 to $95 \%$ of foraging time for ungulates [134]; and 2) a loss in accuracy when discriminating between different sites, as an animal's ability to deal simultaneously with several pieces of information is limited [25]. The trade-off between intake rate maximisation and predator risk minimisation has been widely studied in other species than herbivores (for reviews see $[77,83]$ ). It has been shown that a risky patch had to contain between 8 [66] (rodents) and 25 [87] (ants) times more food than a safe patch to be considered of equal value. For a ruminant, the optimal strategy may consist in selecting sward covers that allow the highest intake rate even if their quality is poor. The animal can then watch for predators when ruminating [86]. Predator risks also modify patch use. Ibex exploited patches with a high predator risk less intensely than safe patches: they consumed 25 vs. $45 \%$ of food resources, respectively [65].

Water location strongly influences feeding site choice, under both dry [146] and temperate conditions $[49,61]$. Topography imposes a physical barrier to movement [117]. Slopes increase the time and energy required to walk a given distance. Cattle and horses avoid slopes above 30 and 50\%, respectively [41]. Topography also offers shelter against bad weather and predators [117]: lactating bighorn ewes prefer the habitats that cannot be reached by predators [11], and the goral, an Himalayan goat, readily chooses steep slopes above 30 degrees [82]. The degree of habitat openness dictates the presence or absence of some animal species: gregarious ungulates avoid woodlands [98] where flock movements and visual contacts are more difficult [62]. The microclimate influences patch selection and movements [121]. Antelopes prefer areas sheltered from strong winds and warmed by the sun [116] because strong winds may limit movements [9].

\section{INFLUENCE OF ANIMAL CHARACTERISTICS}

Herbivores are influenced by some characteristics and state variables in their foraging decisions. These have been reviewed in numerous papers $[26,27]: 1)$ body-size $[45$, $62]$; 2) abilities related to body-size: digestion, selection and walk $[20,22,44,45,54$, $58,91]$; 3) dietary preferences $[27,84,94]$; 4) feeding motivation and physiological state $[29,31,47,85]$. Patch selection also implies that the animal is able to discriminate the relative value of patches. An animal has also to remember the location of the preferred patches in order to return to them. We will now focus on these cognitive abilities and on social behaviour, because these factors have been less thoroughly reviewed [70].

\subsection{Cognitive abilities}

Cognitive abilities include perception, discrimination, learning and memory capacity that enable an animal to adapt to its environment.

Laca et al. [68] observed that cattle foraging on heterogeneous sward covers were 
able to distinguish feeding stations that differed from their surroundings by less than $5 \mathrm{~cm}$ in height. Illius et al. [59] showed that patch selection by sheep foraging on two sward plates was affected by clover content differences (tested factor), but also by sward height differences shorter than $2.7 \mathrm{~cm}$. Yet, Wilmhurst et al. [148] and Illius et al. [60] explained the partial preferences by limitations in the animal's discrimination ability. Spencer et al. [128] constructed a habitat selection model that took into account the differences between animals' abilities to discriminate patches' values. They showed that animals which were sensitive to differences between patch values concentrated in the more profitable patches.

An animal's experiences in the young age (learning with its mother) and over the course of its life (acquisition of feeding habits) influence its foraging behaviour. Four weeks after weaning, lambs preferred plant species they had consumed with their mothers before or during weaning [108]. Dietary imprinting is particularly strong during the transformation of the young ruminant's digestive tract $[23,99]$. Young animals can acquire dietary habits that influence their foraging behaviour for a long period. For example, even after 4 years in common, goats foraging on a tropical savannah selected a diet that was still influenced by their original environment [12]. Conversely, after 3-4 weeks, the preference of lambs for a plant species they used to graze was not any higher than that of inexperienced lambs foraging on the same pasture [90]. In this case, the feeding habits of the test group had probably not become an integral part of their foraging behaviour for a sufficiently long time.

The use of spatial memory for returning to preferred food patches has been demonstrated in many species: squirrels [73], tits [19], deer [42], cattle [6, 7], sheep [32]. It increases an animal's efficiency when exploiting habitat resources [42], by decreasing the time necessary to search for pre- ferred food patches and to sample the various alternatives. Edwards et al. [32] showed that sheep were able to learn and to remember the location of four full bowls within 32 bowls in a $30 \times 45 \mathrm{~m}^{2}$ paddock. In addition, sheep learned the bowl locations more quickly when these were associated with a proximal cue $[32,33]$.

We can distinguish two types of memory: 'reference memory'(at least 20 days for ungulates), which enables animals to remember a patch location and value for a long period, and 'working memory' (at least $8 \mathrm{~h}$ for ungulates) in which are stored the patches that were recently depleted [6-8]. Memory may be 'selective', in that the poor patches would be forgotten less rapidly than the rich ones because large herbivores are particularly sensitive to the negative consequences of their choices $[6,46,55]$. In a risk-limiting strategy, they would try to maximise the possibility of avoiding a net loss [109]. Some patch choice models integrate the memory of patch locations $[8,37$, 117].

Animals' limits in collecting, analysing and processing information [109] force them to use simple 'rules-of-thumb' to help them to select and abandon their feeding sites (e.g., choose the nearest, greenest and tallest patch). Indeed, the potential relative increase in feeding efficiency with a more complete information would not make up for the time/energy required to process it [48, 140]. Milinski [81] even showed that feeding efficiency could be reduced by an information overload and by the weariness and potential mistakes that could result from it.

\subsection{Influence of social organisation}

The influence of social factors on individual's choice increases when the study scale widens (from tussock to habitat). At the 'tussock' level, bite characteristics (geometry, weight, quality) are only slightly affected by the presence of congeners. 
Young red deer have yet a lower prehension biting rate when they forage near a dominant animal, whereas it remains unchanged near a subordinate [132]. Group attraction and movements influence the distances travelled by individual animals [93] and also feeding station choice and use. An animal may graze a station longer if the surrounding ones are not free [10], or it may be driven out of a station by a dominant animal. There may be conflicting demands between staying in the group and moving away to reach a preferred site. Scott et al. [119] observed that in groups of animals reared together since their young age, social attraction was stronger than the attraction for pre-
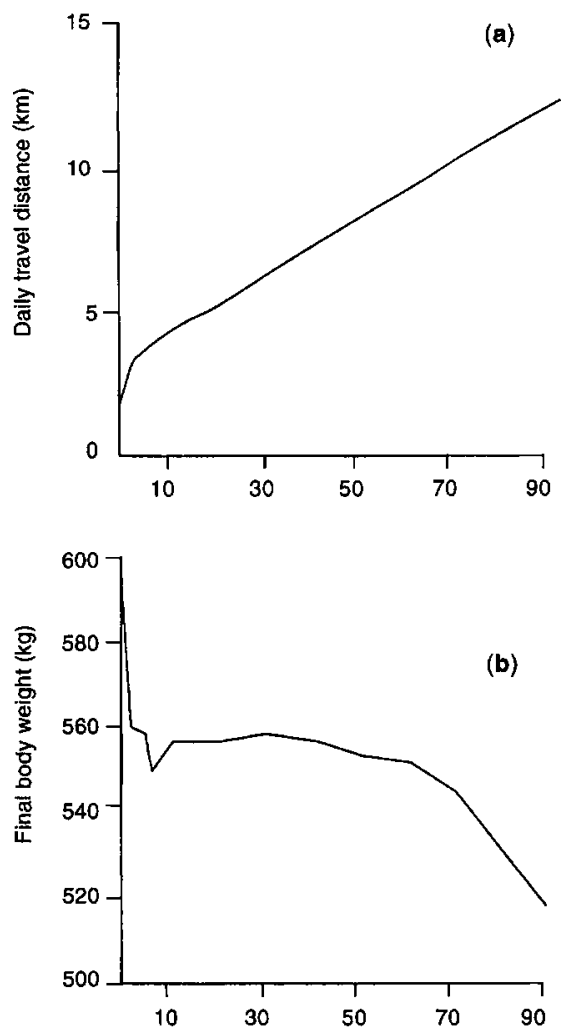

Figure 5. Simulated ungulate group size effects on daily travel distance (a), and final body weight (b). The simulation period was 100 days, with 100 vegetation patches randomly distributed over a $100 \times 100$ grid. Initial body weight of cattle was $500 \mathrm{~kg}$ [141]. ferred patches. Conversely, in newly constituted groups, animals would move away to reach preferred feeding sites. The result of the conflict between social and feeding motivations not only depends on the strength of relations between individuals in the group, but also on their knowledge of the environment. In a new environment, lambs are strongly influenced by congeners' location to choose their feeding sites. In a familiar environment, they will more readily express their preferences [120].

Group foraging enables animals to minimise predator risks $[40,62]$ and to take advantage of congeners' past experience in locating sites and determining their value $[78,135,149]$. Gregariousness also has a cost in terms of exploitative and interference competition, aggressiveness, judgement mistakes by the 'leader'. Wallis de Vries [141] modelled the effect of group size on the number of patches visited and distance travelled per day and per cow in a 100 -site environment. When group size increased, patch resource depletion was faster. Consequently, the animals moved more frequently and had to walk a longer distance to meet their nutritional requirements (figure $5 a$ ). Above a given number of individuals in the group, depletion of available resources per individual strongly hindered weight gain during the 100-day simulation (figure $5 b$ ). Fritz and de Garine-Wichatitsky [40] showed that antelopes selected their patches (bushes) according to the biomass of the accessible leaves but also to the number of animals in their group. They anticipated the consequences of feeding competition by selecting patches whose value was proportional to group size. Hence, group size is a factor to consider for understanding how an individual perceives patch value.

\section{CONCLUSION}

Herbivore foraging behaviour can be divided into a series of decisions that direct animals to a habitat where they choose and 
exploit feeding sites, feeding stations and bites. These decisions are influenced by numerous factors including food characteristics, the abiotic environment and animal factors (table II). The effect of non-alimentary factors on habitat use depends on the type of animal (domestic/wild), its environment (temperate/tropical), and its social organisation (more or less gregarious). Animals have to make trade-offs, in particular between intake and predator risks, between quantity and quality, etc. As in a chemical equilibrium, the relative importance of the different factors could be estimated by determining at which moment feeding activity reaches an equilibrium, for example between a rich but risky patch and a poor but safe patch (or a rich but distant patch compared to a poor but close patch) [66]. In all cases, feeding efficiency remains the primary goal of patch selection and use [71].

Optimal foraging theory seems to be a valid approach to study resource exploitation by herbivores. In controlled situations involving simple choices, with a minimum of constraints, animals tend to exploit patches that enable them to maximise their intake rate.

Other determinants of foraging behaviour can also be reported. Animals may not seek

Table II. Summary of objectives and factors influencing animals' decisions on the different spatio-temporal scales $[8,122]$.

\begin{tabular}{llllll}
\hline $\begin{array}{l}\text { Spatial } \\
\text { level }\end{array}$ & $\begin{array}{c}\text { Temporal } \\
\text { level }\end{array}$ & Definition & $\begin{array}{l}\text { Some potential } \\
\text { selection } \\
\text { criteria }\end{array}$ & $\begin{array}{l}\text { Potential factors } \\
\text { that may affect } \\
\text { foraging behaviour }\end{array}$ & $\begin{array}{l}\text { Hypothetical } \\
\text { foraging goals }\end{array}$ \\
\hline Bite & $1-2 \mathrm{~s}$ & $\begin{array}{l}\text { Jaw, tongue } \\
\text { and neck } \\
\text { movements }\end{array}$ & $\begin{array}{l}\text { Nutrients, } \\
\text { Toxins, } \\
\text { Secondary } \\
\text { compounds, }\end{array}$ & $\begin{array}{l}\text { Intake rate, } \\
\text { Diet selection, } \\
\text { Post-ingestive } \\
\text { consequences }\end{array}$ & $\begin{array}{l}\text { Nutrient } \\
\text { maximisation, } \\
\text { Toxin } \\
\text { minimisation, }\end{array}$ \\
Feeding and structure \\
station
\end{tabular}


to optimise, but remain content with satisfying their minimal requirement for survival and reproduction, in particular when these needs are low [88]. 'Optimal' or 'satisfying', animal choices are also certainly influenced by the pleasant feelings eating produces (gustative, olfactory, or tactile) [100]. Difficult to quantify, hedonism (the search for pleasant feelings) probably has a slighter influence on patch selection (the animal may still remember the location of the most 'pleasant' grazing patches) than on patch use (selection of green leaves, of particular plant species, etc.). Herbivores also seem able, in a innate (euphagia, [100]) and/or learned (learning of post-ingestive effects of food item choices, [101]) manner, to determine the nutritional (sodium, phosphorus, proteins, etc.) and toxic (tannins, cyanogens, etc.) characteristics of the plants they ingest. In this case, patch selection could be partly attributed to the desire to ingest a balanced diet ('nutritional wisdom'; [45, 80, 93, 100, $136,140,143,144]$ ).

It appeared that patches' nutritional value, and also their spatial distribution, are essential factors affecting the way ungulates exploit their habitat. A better understanding of the rules governing resource use by individuals, and the distribution of the individuals of a population in the habitat, has both theoretical and practical interest. It should help practitioners to better manage herbivore populations and their vegetation requirements. Decision assisting models have already begun to integrate guidelines for resource selection and use with the aim of predicting "where animals are likely to graze' and 'what they will ingest on each patch type' [4], as well as the consequences for the pasture vegetation cover [141].

\section{REFERENCES}

[1] Anderson D.J., Optimal foraging and the traveling salesman, Theor. Pop. Biol. 24 (1983) $145-159$.

[2] Arditi R., Dacorogna B., Optimal foraging in nonpatchy habitats. I. Bounded one-dimensional resource, Math. Biosci. 76 (1985) 127-145.
[3] Arditi R., Dacorogna B., Optimal foraging on arbitrary food distribution and the definition of habitat patches, Am. Nat. 131 (1988) 837-846.

[4] Armstrong H.M., Predicting the effects of large herbivores on hill vegetation in the UK. The art and graph of modelling in applied biology, Asp. Appl. Biol. 26 (1991) 217-220.

[5] Aström M., Lundberg P., Danell K., Partial prey consumption by browsers: trees as patches, $\mathbf{J}$. Anim. Ecol. 59 (1990) 287-300.

[6] Bailey D.W., Rittenhouse L.R., Hart R.H., Richards R.W., Characteristics of spatial memory in cattle, Appl. Anim. Behav. Sci. 23 (1989) 331-340.

[7] Bailey D.W., Rittenhouse L.R., Hart R.H., Swift D.M., Richards R.W., Association of relative food availabilities and locations by cattle, J. Range Manag. 42 (1989) 480-482.

[8] Bailey D.W., Gross J.E., Laca E.A., Rittenhouse L.R., Coughenour M.B., Swift D.M., Sims P.L., Mechanisms that result in large herbivore grazing distribution patterns, J. Range Manage 49 (1996) 387-397.

19] Bao J., Giller P.S., Kett J. J., The effect of mik production level on grazing behaviour of friesian cows under valuable pasture conditions, Irish $\mathbf{J}$. Agric. Food Res. 31 (1992) 23-33.

[10] Bazely D.R., Foraging behaviour of sheep ( Ovis aries $\mathbf{L}$.) grazing on swards of perennial ryegrass (Lolium perenne L.), Thesis, Univ. Oxford, 1988.

[11] Berger J., Pregnancy incentives, predation constraints and habitat shifts: experimental and field evidence for wild bighorn sheep, Anim. Behav. 41 (1991) 61-77.

[12] Biquand S., Biquand-Guyot V., The influence of peers, lineage and environment on food selection of the criollo goat (Capra hircus), Appl. Anim. Behav. Sci. 34 (1992) 231-245.

[13] Black J.L., Kenney P.A. Factors affecting diet selection by sheep. II. Height and density of pasture, Aust, J. Agric. Res. 35 (1984) 565-578.

[14] Bond A.B., Optimal foraging in a uniform habitat: the search mechanism of the green lacewing, Anim. Behav, 28 (1980) 10-19.

[15] Bryant D., Turner A.K. Central place foraging by swallows: the question of load size, Anim. Behav. 30 (1982) 845-856.

[16] Carter M.C., Dixon A.F.G., Habitat quality and the foraging behaviour of Coccinellid larvae, J. Anim. Ecol. 51 (1982) 865-878.

[17] Charnov E.L., Optimal foraging, the marginal value theorem, Theor. Pop. Biol. 9 (1976) 129-136.

[18] Clarke J.L., Welch D., Gordon I.J., The influence of vegetation pattern on the grazing of heather moorland by red deer and sheep. I. The location of animals on grass/heather mosaics, J. Appl. Ecol. 32 (1995) 166-176.

[19] Cowie R. J., Optimal foraging in great tits (parus major), Nature 268 (1977) 137-139. 
[20] Demment M.W., Greenwood G.B., Forage ingestion: effects of sward characteristics and body size, J. Anim. Sci. 66 (1988) 2380-2392.

[21] Demment M.W., Laca E.A., The grazing ruminant: models and experimental techniques to relate sward structure and intake, in: $M$. Edmonton, Proceedings VII, World Conf. Anim. Prod., Canada, 1993, 439-460.

[22] D'Hour P., Hauwuy A., Coulon. J.B., Garel J.P., Walking and dairy cattle performance. Ann Zoot. 43 (1994) 369-378.

[23] Distel R.A., Villalba J.J., Laborde H.E., Effects of early experience on voluntary intake of lowquality roughage by sheep, J. Anim. Sci. 72 (1994) 1191-1195.

[24] Distel R.A., Laca E.A., Griggs T.C., Demment M.W., Patch selection by cattle: maximization of intake rate in horizontally heterogeneous pastures, Appl. Anim. Behav. Sci. 45 (1995) 11-21.

[25] Dukas R., Ellner S., Information processing and prey detection, Ecology 74 (1993) 1337-1346.

[26] Dumont B., Déterminisme des choix alimentaires des herbivores au pâturage : principales théories, Inra Prod. Anim. 8 (1995) 285-292.

[27] Dumont B., Diet preferences of herbivores at pasture, Ann. Zoot. 46 (1997) 105-116.

[28] Dumont B., Petit M., An indoor method for studying the preferences of sheep and cattle at pasture, Appl. Anim. Behav. Sci. 46 (1995) 67-80.

[29] Dumont B., Petit M., D'Hour P., Choice of sheep and cattle between vegetative and reproductive cocksfoot patches, Appl. Anim. Behav. Sci. 43 (1995) 1-15.

[30] Dumont B., Dutronc A., Petit M., How readily will sheep walk for a preferred forage? J. Anim. Sci. 76 (1998) 965-971.

[31] Edwards G.R., Newman J.A., Parson A.J., Krebs J.R., Effects of the scale and spatial distribution of the food resource and animal state on diet selection: an example with sheep, J. Anim. Ecol. 63 (1994) 816-826.

[32] Edwards G.R., Newman J.A., Parsons A.J., Krebs J.R., The use of spatial memory by grazing animals to locate food patches in spatially heterogeneous environments: an example with sheep, Appl. Anim. Behav. Sci. 50 (1996) 147-160.

[33] Edwards G.R., Newman J.A., Parsons A.J., Krebs J.R., Use of cues by grazing animals to locate food patches: an example with sheep, Appl. Anim. Behav. Sci. 51 (1997) 59-68.

[34] El Aich A., Moukadem A., Rittenhouse L.R., Feeding station behavior of free-grazing sheep, Appl. Anim. Behav, Sci. 24 (1989) 259-265.

[35] Emlen J.M., The role of time and energy in food preference, Am. Nat. 100 (1966) 611-617.

[36] Focardi S., Marcellini P., Montanaro P., Do ungulates exhibit a food density threshold? A field study of optimal foraging and movement patterns, J. Anim. Ecol. 65 (1996) 606-620.
[37] Folse L.J., Packard J.M., Grant W.E., AI modelling of animal movements in a heterogeneous habitat, Ecol. Model. 46 (1989) 57-72.

[38] Forman R.T.T, Godron M., Landscape ecology, Wiley, New York, 1986.

[39] Fretwell S.D., Lucas H.L., On terrestrial behaviour and other factors influencing habitat distribution in birds, Acta Bioth. 19 (1970) 16-36.

[40] Fritz H., De Garine-Wichatitsky M., Foraging in a social antelope: effects of group size on foraging choices and resource perception in impala, J. Anim. Ecol. 65 (1996) 736-742.

[41] Ganskopp D., Vavra M., Slope use by cattle, feral horses, deer and bighorn sheep, Northw. Sci. 61 (1987) 74-81.

[42] Gillingham M.P., Bunnell F.L., Effects of learning on food selection and searching behaviour of deer, Can. J. Zool. 67 (1989) 24-32.

[43] Goddard J., Food preferences of two black rhinoceros populations, E. Afr. Wildl. J. 6 (1968) $1-18$.

[44] Gordon I.J., Illius A.W., Incisor arcade structure and diet selection in ruminants, Funct. Ecol. 2 (1988) 15-22.

[45] Gordon I.J., Illius A.W., The nutritional ecology of African ruminants: a reinterpretation, $\mathrm{J}$. Anim. Ecol. 65 (1996) 18-28.

[46] Grandin T., Odde K.G., Schutz D.N., Behms L.M., The reluctance of cattle to change a learned choice may confound preference tests, Appl. Anim. Behav. Sci. 39 (1994) 21-28.

[47] Greenwood G.B., Demment M.W., The effect of fasting on short-term cattle grazing behaviour, Grass For. Sci. 43 (1988) 377-386.

[48] Gross J.E., Zank C., Hobbs N.T., Spalinger D.E., Movement rules for herbivores in spatially heterogenous environments: responses to small scale pattern, Landscape Ecol. 10 (1995) 209-217.

[49] Hart R.H., Bissio J., Samuel M.J., Waggoner Jr. J.W., Grazing systems, pasture size, and cattle grazing behavior, distribution and gains, $J$. Range Manag. 46 (1993) 81-87.

[50] Hirvonen H., Ranta E., Within-bout dynamics of diet choice, Behav. Ecol. 7 (1996) 494-500.

[51] Hodges C.M., Optimal foraging in bumblebees: hunting by expectation, Anim. Behav. 29 (1981) 1166-1171.

[52] Hodgson J., Jamieson W.S., Variations in herbage mass and digestibility, and the grazing behavior and herbage intake of adult cattle and weaned calves, Grass For. Sci. 36 (1981) 39-48.

[53] Hodgson J., Forbes T.D.A., Armstrong R.H., Beattie M.M., Hunter E.A., Comparative studies of the ingestive behaviour and herbage intake of sheep and cattle grazing indigenous hill plant commmunities, J. Appl. Ecol. 28 (1991) 205-227.

[54] Hofmann R.R., Evolutionary steps of ecophysiological adaptation and diversification of rumi- 
nants: a comparative view of their digestive system, Oecologia 78 (1989) 443-457.

[55] Hosoi E., Rittenhouse L.R., Swift D.M., Richards R.W., Foraging strategies of cattle in a Y-maze: influence of food availability, Appl. Anim. Behav. Sci. 43 (1995) 189-196.

156] Houston I.A., McNamara J.M., The ideal free distribution when competitive abilities differ: an approach based en statistical mechanics, Anim. Behav. 36 (1988) 166-174.

[57] Hughes T.P., Sykes A.R., Poppi D.P., Hodgson J., The influence of sward structure on peak bite force and bite weight in sheep, Proc. NZ Soc. Anim. Prod. 51 (1991) 153-158.

[58] Illius A.W., Gordon I.J., The allometry of food intake in grazing ruminants, J. Anim. Ecol. 56 (1987) $989-999$.

[59] Illius A.W., Clark D.A., Hodgson J., Discrimination and patch choice by sheep grazing grassclover swards, J. Anim. Ecol. 61 (1992) 183-194.

[60] Illius A.W., Gordon I.J., Elston D.A., Milne J.D., Diet selection in grazing ruminants: A test of rate maximization, Ecology (1998), in press.

[61] Irving B.D., Rutledge P.L., Bailey A.W., Neath A., Chanasyk, D.S., Grass utilization and grazing distribution within intensively managed fields in Central Alberta, J, Range Manag. 48 (1995) 358-361.

[62] Jarman P.J., The social organisation of antelope in relation to their ecology, Behaviour 48 (1974) $215-267$

[63] Jiang Z., Hudson R.J., Optimal grazing of wapiti (Cervus elaphus) on grassland: patch and feeding station departure rules, Evol. Ecol. 7 (1993) $488-498$.

[64] Kennedy M., Gray R.D., Can ecological theory predict the distribution of foraging animals? A critical analysis of experiments on the ideal free distribution, Oikos 68 (1993) 158-166.

[65] Kotler B.P., Gross J.E., Mitchell W.A., Applying patch use to assess aspects of foraging behavior in nubian ibex, J. Wild. Manag. 58 (1993) 299-307.

[66] Kotler B.P., Blaustein L., Titrating food and safety in a heterogeneous environment: when are the risky and safe patches of equal value? Oikos 74 (1995) 251-258.

[67] Laca E.A, Demment M.W., Herbivory: the dilemma of foraging in a spatially heterogeneous food environnement, in: Palo R.T., Robbins C.T. (Éds.), Plant defenses against mammalian herbivory, CRC Press, Boca Raton, Florida, 1991, 29-44.

[68] Laca E.A., Distel R.A., Griggs T.C., Deo G., Demment M.W., Field test of optimal foraging with cattle: the marginal value theorem successfully predicts patch selection and utilisation, XVII International Grassland Congress, 8-21 Feb. 1993, Palmerston North, NZ, 1993, 709-710.

[69] Laca E.A., Distel R.A., Griggs T.C., Demment M.W., Effect of canopy structure on patch depression by grazers, Ecology 75 (1994) 706-716.

[70] Laca E.A, Demment M.W., Foraging strategies of grazing animals, in: Hodgson J., Illius A.W., (Eds.), The ecology and management of grazing systems, 1996, pp. 137-158.

[71] Langvatn R., Hanley T.A., Feeding-patch choice by red deer in relation to foraging efficiency: An experiment, Oecologia 95 (1993) 164-170.

[72] Lea S.E., Foraging and reinforcement schedules in the pigeon: optimal and non-optimal aspects of choice, Anim. Behav. 27 (1979) 875-886.

[73] Lewis A.R., Patch use by gray squirrels and optimal foraging, Ecology 61 (1980) 1371-1379.

[74] Lima S.L., Downy woodpecker foraging behavior: efficient sampling in stochastic environments, Ecology 61 (1984) 1371-1379.

[75] MacArthur R.H., Pianka E.R., On optimal use of a patchy environment, Am. Nat. 100 (1966) 603.

[76] MacNair J.N., A class of patch-use stategies, Am. Zool. 23 (1983) 303-313.

[77] MacNamara J., Alasdair M., Houston I., The effect of a change in foraging options on intake rate and predation rate, Am. Nat. 144 (1994) 978-1000.

[78] MacQuoid L.M., Galef Jr., Social influences on feeding site selection by burmese fowl (Gallus gallus), J. Comp. Psychol. 2 (1992) 137-141.

[79] Mangel M., Clark C.W., Towards a unified foraging theory, Ecology 67 (1986) 1127-1138.

[80] Maizeret C., Stratégies alimentaires des chevreuils : les fondements écologiques d'une diversification du régime, Acta Oecol. Oecol. Appl. 9 (1988) 191-211.

[81] Milinski M., Information overload and food selection, Hughes R.N. (Ed.), Behavioural mechanism of food selection, NATO ASI series G, 20 (1990) 721-736.

[82] Mishra C., Johnsengh A.J.T., On habitat selection by the goral Nemorhaedus geral bedfodi (bovidae arhodactyla), J. Zool. 240 (1996) 573-580.

[83] Newman J.A., Patch use under predation hazard: foraging behavior in a simple stochastic environment, Oikos 61 (1991) 29-44.

[84] Newman J.A., Parsons A.J., Penning P.D., A note on the behavioural strategies used by grazing animals to alter their intake rates, Grass For. Sci. 49 (1994) 502-505.

[85] Newman J.A., Penning P.D., Parsons A.J., Harvey A., Orr R.J., Fasting affects intake behaviour and diet preference of grazing sheep, Anim. Behav. 47 (1994) 185-193.

[86] Newman J.A., Parsons A.J., Thornley J.H.M., Penning P.D., Krebs J.R., Optimal diet selection by a generalist grazing herbivore, Funct. Ecol. 9 (1995) 255-268.

[87] Nonacs R., Dil] L. M., Mortality risk vs food quality trade-offs in a common currency: patch preferences, Ecology 71 (1990) 1886-1892.

[88] Nonacs R., Is satisficing an alternative to optimal foraging theory? Oikos 63 (1993) 312-317. 
[89] Novellie P.A., Comparison of the foraging strategies of blesbok and springbok on the transvaal highveld, J. Wild, Res. 8 (1978) 137-144.

[90] Olson B.E., Wallander R.T., Thomas V.M., Kott R.W., Effect of previous experience on sheep grazing leafy spurge, Appl. Anim. Behav. Sci. 50 (1996) 161-176.

[91] O'Reagain P.J., Stuart-Hill G.C.,. The effect of plant structure on the acceptability of different grass species to cattle and sheep grazing african sour grassveld, in Congrès International des Terres de Parcours, Montpellier, France, 1991, pp. $489-491$.

[92] Orians G.H., Pearson N.E., On the theory of central place foraging, in: Hom D.J., Stairs G.R., Mitchell R.D. (Eds.), Analysis of Ecological Systems, Columbus, Ohio State Univ. Press, 1979, pp. 155-177.

193] Owen-Smith R.N., Novellie P., What should a clever ungulate eat? Am. Nat. 119 (1982) 151-178.

[94] Parsons A.J., Thornley J.H.M., Newman J.A., Penning P.D., A mechanistic model of some physical determinants of intake rate and diet selection in a two-species temperate grassland sward, Funct. Ecol. 8 (1994) 187-204.

[95] Pickett S.T.A., White P.S., The ecology of natural disturbance and patch dynamics, Academic Press, New York, 1985.

[96] Prache S., Roguet C., Petit M., How degree of selectivity modifies foraging behaviour of dry ewes on reproductive compared to vegetative sward structure, Appl. Anim. Behav. Sci. 57 (1998) 91-108.

[97] Prache S., Peyraud J.L., Préhensibilité de l'herbe pâturée chez les bovins et les ovin, Inra Prod. Anim. 10 (1997) 377-390.

[98] Pratt R.M., Putman R.J., Ekins J.R., Edwards P.J., Use of habitat by free-ranging cattle and ponies in the New Forest, southern England, J. Appl. Ecol. 23 (1986) 539-557.

[99] Provenza F.D., Balph D.F., Diet learning by domestic ruminants: Theory, evidence and practical implications, Appl. Anim. Behav. Sci. 18 (1987) 211-232.

[100] Provenza F.D., Balph D.F., Applicability of five diet-selection models to various foraging challenges ruminants encounter, in: Hughes R.N. (Ed.), Behavioural Mechanisms of Food Selection, Springer Verlag, Berlin, 1990, pp. 423-460.

[101] Provenza F.D., Postingestive feedback as an elementary determinant of food preference and intake in ruminants, J. Range Manag. 48 (1995) 2-17.

[102] Pyke G.H., Pulliam H.R., Charnov E.L., Optimal foraging: a selective review of theory and tests, Q. Rev. Biol. 52 (1977) 137-153.

[103] Pyke G.H., Optimal foraging in hummingbirds: testing the marginal value theorem, Am. Zool. 18 (1978) 739-752.
[104] Pyke G.H., Optimal foraging in bumblebees: rule of movement between flowers within inflorescences, Anim. Behav. 27 (1979) 1167-1181.

[105] Pyke G.H., Optimal foraging in hummingbirds: rule of movement between inflorescences, Anim. Behav. 29 (1981) 889-896.

[106] Pyke G.H., Optimal travel speeds of animals, Am. Nat. 118 (1981) 4.

[107] Pyke G.H., Optimal foraging theory: a critical review, Annu. Rev. Ecol. Syst. 15 (1984) 523-575.

[108] Ramos A., Tennessen T., Effect of previous grazing experience on the grazing behaviour of lambs, Appl. Anim. Behav. Sci. 33 (1992) 43-52.

[109] Real L.A., Animal choice behavior and the evolution of cognitive architecture, Science 253 (1991) $980-986$.

[110] Roguet C., Stratégie de pâturage des ovins à l'échelle de la station alimentaire : utilisation, déplacements, thèse Inap-G., 1997, 111 p.

[111] Roguet C., Prache S., Petit M., Development of a methodology for studying feeding station behaviour of grazing ewes, Appl. Anim. Behav. Sci. 55 (1998) 307-316.

[112] Roguet C., Prache S., Petit M., Feeding station behaviour of ewes in response to forage availability and sward phenological stage, Appl. Anim. Behav. Sci. 56 (1998) 187-201.

[113] Roese J.H., Risenhoover K.L., Folse L.J., Habitat heterogeneity and foraging efficiency: an individual-based model, Ecol. Model. 57 (1991) 133-143.

[114] Rominger E. M., Robbins C. T., Evans M. A., Winter foraging ecology of woodland in northearstern Washington, J. Wild. Manag. 60 (1996) 719-728.

[115] Ruyle G.B., Dwyer D., Feeding stations of sheep as an indicator of diminished forage supply, $\mathbf{J}$. Anim. Sci. 61 (1985) 349-353.

[116] Ryder T.J., Irwin L.L., Winter habitat relationships of pronghorns in southcentral Wyoming, J. Wild. Manag. 51 (1987) 79-85.

[117] Saarenmaa H., Stone N.D., Folse L.J., Packard J.M., Grant W.E., Makela M.E., Coulson R.N., An artificial intelligence modelling approach to simulating animal/habitat interactions, Ecol. Model. 44 (1988) 125-141.

[118] Schaefer J.A., Messier F., Winter foraging by muskoxen: a hierarchical approach to patch residence time and cratering behaviour, Oecologia 104 (1995) 39-44.

[119] Scott C. B., Provenza F. D., Banner R. E., Dietary habits and social interactions affect choice of feeding location by sheep, Appl. Anim. Behav. Sci. 45 (1995) 225-237.

[120] Scott C. B., Banner R. E., Provenza F. D., Observations of sheep foraging in familiar and unfamiliar environments: familiarity with the environment influences diet selection, Appl. Anim. Behav. Sci. 49 (1996) 165-171. 
[121] Senft R.L., Rittenhouse L.R., Woodmansee R.G., Factors influencing selection of resting sites by cattle on shortgrass steppe, J. Range Manag. 38 (1985) 295-299.

[122] Senft R.L., Coughenour M.B., Bailey D.W., Rittenhouse L.R., Sala O.E., Swift D.M., Large herbivore foraging and ecological hierarchies, BioScience 37 (1987) 789-799.

[123] Shipley L.A., Spalinger D.E., Influence of size and density of browse patches on intake rates and foraging decisions of young moose and white-tailed deer, Oecologia 104 (1995) $112-121$.

[124] Sih A., Optimal foraging: partial consumption of prey, Am. Nat. 116 ( 1980) 281-290.

[125] Slater P.J.B., Lester N.P., Minimising diers in splitting behaviour into beats, Behaviour 79 (1982) 153-161.

[126] Smith J.N.M., Sweatman H.P.A., Food-searching behavior of titmice in patchy environments, Ecology 55 (1974) 1216-1232.

[127] Spalinger D.E., Hobbs N.T., Mechanisms of foraging in mammalian herbivores: new models of functional response, Am. Nat. 140 (1992) 325-348.

[128] Spencer H.G., Kennedy M., Gray R.D., Perceptual constraints on optimal foraging: the effects of variation among foragers, Evol. Ecol. 10 (1996) 331-339.

[129] Staddon J. E. R., Adaptive behaviour and learning, Cambridge Univ. Press, Cambridge, UK, 1983.

[130] Stephens D.W, Krebs J.R., Foraging theory, Princeton University Press, Princeton, 1986.

[131] Stuth J.W., Foraging behavior, in: Heitschmidt R.K., Stuth J.W. (Eds.), Grazing Management an Ecological Perspective, Timber Press, Portland/Oregon, 1991, pp. 64-83.

[132] Thouless C.R., Feeding competition between grazing red deer hinds, Anim. Behav. 40 (1990) $105-111$.

[133] Turner M.G., Wu Y., Romme W.H., Wallace L.L., A landscape simulation model of winter foraging by large ungulates, Ecol. Model. 69 (1993) 163-184.

[134] Underwood R., The feeding behaviour of grazing African ungulates, Behaviour, 84 (1983) 195-243.

[135] Valone T.J., Group foraging, public information, and patch estimation, Oikos, 56 (1989) $357-363$.
[136] Van Wieren S.E., Do large herbivores select a diet that maximizes short-term energy intake rate'? Forest Ecol. Manag. 88 (1996) 149-156.

[137] Vivas H.J., Saether B.E., Interactions between a generalist herbivore, the moose alces alces, and its food resources: an experimental study of winter foraging behaviour in relation to browse availability, J. Anim. Ecol. 56 (1987) 509-520.

[138] Wallace L.L., Turner M.G., Romme W.H., O'Neill R.V., Wu Y., Scale of heterogeneity of forage production and winter foraging by elk and bison, Landscape Ecol. 10 (1995) 75-83.

[139] Wallis de Vries M.F., Daleboudt C., Foraging strategy of cattle in patchy grassland, Oecologia 100 (1994) 98-106.

[140] Wallis de Vries M.F., Schippers P., Foraging in a landscape mosaic: selection for energy and minerals in free-ranging cattle, Oecologia 100 (1994) 107-117.

[141] Wallis de Vries M.F., Resource distribution patterns of ungulate foraging behaviour, Forest Ecol. Manag. 88 (1996) 167-177.

[142] Ward D., Saltz D., Foraging at different spatial scales: dorcas gazelles foraging for lilies in the Negev desert, Ecology 75 (1994) 48-58.

[143] Westoby M., An analysis of diet selection by large generalist herbivores, Am. Nat. 108 (1974) 290-304.

[144] Westoby M., What are the biological bases of varied diets? Am. Nat. 112 (1978) 627-631.

[145] Wiens J.A., Population responses to patchy environments, Annu. Rev. Ecol. Syst. 7 (1976) $81-120$.

[146] Williamson D., Williamson J., Ngwamotsoko K.T., Wildebeest migration in the Kalahari, Afr. J. Ecol. 26 (1988) 269-280.

[147] Wilmshurst J.F., Fryxell J.M., Patch selection by red deer in relation to energy and protein intake: a re-evaluation of Langvatn and Hanley's (1993) results, Oecologia 104 (1995) 297-300.

[148] Wilmshurst J.F., Fryxell J.M., Hudson R.J., Forage quality and patch choice by wapiti ( $\mathrm{Cer}$ vus elaphus), Behav. Ecol. 6 (1995) 209-217.

[149] Zemel A., Lubin Y., Inter-group competition and stable group sizes, Anim. Behav. 50 (1995) 485-488.

[150] Kotliar N.B., Wiens J.A., Multiple scales of patchiness and patch structure: a hierarchical framework for the study of heterogeneity, Oikos 59 (1990) 253-260. 